\title{
A PÓS-MODERNIDADE E O GEÓGRAFO ${ }^{1}$
}

\author{
Georges Benko
}

\author{
À Paul Claval, \\ por pensar a geografia, \\ uma homenagem amigável.
}

A modernidade e a pós-modernidade nāo são na origem conceitos das ciências sociais. Podemos, antes, qualificar esses termos como os modos (ou os fundamentos) de civilização específicos. Apesar de suas diversidades simbólicas e geográficas, os dois termos se impōem no Ocidente. Entretanto, essas noçōes permanecem confusas, prestando-se a diversas interpretaçōes e conotando, globalmente, toda uma evoluçāo histórica e uma mudança de mentalidade. Inextricavelmente, nós navegamos desde os anos 1970 entre mitos e realidades em todos os domínios: as artes, a arquitetura, os costumes, a ideologia, a política, etc. Modernidade e pós-modernidade nasceram de certas perturbaçōes profundas da organização social, econômica e política, realizando-se no nível dos costumes, do modo de vida e da cotidianidade.

Como não são conceitos de análise, não existe lei da modernidade nem da pós-modernidade. Só há traços nos dois casos. As morais canônicas das mudanças que se opōem. É "The Tradition of New" dizia Harold Rosenberg em 1960. Elas funcionam como idéias-motoras e como ideologias mestras, sublimando as contradiçōes da história nos efeitos da civilização. Elas estão ligadas às crises históricas de estruturas. Modernidade e pósmodernidade exprimem de modo ambíguo as crises da civilização e dos conhecimentos, numa fuga para a frente contínua. Ambas querem impor uma regulação cultural nova. É por esta razāo que elas se encontram no centro dos debates atuais em todos os domínios das ciências humanas.

\section{O mundo em "pós"}

Aqueles que falam de pós-modernidade, freqüentemente, focalizam sua atenção na revolução cultural e na revolução industrial. A longa história dessas duas revoluçōes parece comportar uma ruptura essencial que marca um antes a modernidade e um depois - a pós-modernidade.

Sem que possamos data-la com precisão, a ruptura cultural aparece com evidência por volta de 1968. O que observamos aponta, sobretudo, uma mudança dos valores: a anarquia parece preferivel à hierarquia, o jogo ao projeto estruturado, a "desconstrução" à criação, a liberdade individual aos valores coletivos, etc.

No domínio econômico, é a crise que esboça a guinada. A sociedade industrial torna-se pósindustrial e o sistema produtivo fordista dá lugar ao pós-fordismo. As tecnologias de informação e de comunicaçáo invadem o mundo econômico e os lares. No campo político, o Estado-providência desaparece, assim como os paises comunistas. O Estado liberal e o mercado dominam. Podemos di- 
zer que a pós-modernidade caracteriza assim a passagem das certezas de uma ciência positiva triunfante a uma incerteza generalizada.

Em suma, todos os que falam de pósmodernidade constatam que o mundo de hoje atravessa uma grave crise. Podemos ainda falar de modernidade quando todas as certezas da velha modernidade desabaram, incluindo as do domínio científico? A epistemologia das ciências assim atravessa uma grave crise, uma crise da qual Paul Feyerabend é sem dúvida uma das melhores testemunhas.

A crise da epistemologia científica é o sintoma de uma mudança maior. (Notemos que "o caso Sokal" 2 não é estranho a esse problema). Entretanto, devemos pensar que uma tal crise, tão profunda e generalizada, inaugura uma nova era histórica? Talvez a crise seja tão importante para conduzir a uma nova visão de mundo? Talvez...

Parece difícil saber se o pós-modernismo corresponde a uma autêntica mudança de epistémé, ou de paradigma, no sentido de Kuhn; ou se deu nascimento a formas originais, ou se está satisfeito em reciclar antigos procedimentos num contexto diferente. Existe continuidade ou ruptura com o modernismo, se sim, seria positiva ou negativa?

No espaço de vinte anos, o conceito de pósmodernidade tornou-se um dos mais remarcáveis entre aqueles, em evolução, nas discussōes relativas à arte, à literatura ou à teoria social. A noção de "pós-modernidade" reúne uma rede de conceitos e modelos de pensamentos em "pós", e aqui podemos elencar alguns exemplos: sociedade pósindustrial (Bell, Touraine), pós-estruturalismo (Bonnett, Dews, Harland, Pratt), pós-fordismo (Amin, Harvey), pós-comunismo (Fejtö), pós-marxismo (Peet, Watts), pós-cristão (Poulat, Lambert), pós-hierárquico (Mills), pós-burocrático (Heckscher, Donnellon), pós-liberalismo (Gray), pós-desenvolvimento (Escobar), pós-freudiano (Amaret), pósfeminismo (Murray), pós-imperialismo (Schuurman), pós-filosófico (Fougeyrollas), pós-urbano (Kling), pós-colonial (Young, Harasym, Aschcroft), pós-capitalista (Vakaloulis), entre as expressões mais correntemente evocadas. Uma boa parte das teorias "se moderniza" assim em "pós": Simmel Pós-modernizado (Weinstein), a localização dos estabelecimentos pós-Weberiana (Scottt, Benko), a teoria pós-impasse (Schuurman), a cultura pós-televisão (D’Agostino, Tafler), e a sociologia lararsfeldianna (Pasquier). Mesmo a administração pública ou ainda o marketing tornam-se pós-modernos (Fox, Miller, Brown). A pós-modernidade coloca-se em relação com: o feminismo (Bondi, Nicholson, Soper), a ecologia (Bech, Ferry), o ambiente (Gangy), a religiāo (Bhatt, Gellner), a planificação (Dear, Soja), o espaço (Bonnett, Harvey), etc. Geografia, sociologia, filosofia, literatura, arquitetura, artes plásticas entraram no período pós-moderno. O "pós" é incontornavel! O fim do século XX se conjuga em "pós". Mal estar ou renovaçāo das ciências sociais, das artes, da filosofia estão em voga.

A lógica da modernidade é aquela dos três grandes dispositivos e de suas pressões: produção-organização-poder; sua retórica é aquela dos movimentos de ruptura e de pesquisa, das tensóes em direção à novidade e ao inédito. Elas se opõem uma à outra, elas se contradizem no afrontamento, elas assim provocaram uma crise da representação, uma perturbação das referências, uma explosão no seio da sociedade e da cultura que aparecem, assim, mais fragmentadas. A corrente pósmodernista introduziu-se numa brecha, no curso dos anos sessenta-setenta, levando em conta o contraditório a ponto de marcar sua própria denominação. Como se situar simultaneamente no tempo presente e além, superando a modernidade imediata?

Na origem, uma crítica das convenções, das formas e dos objetivos definem a teoria e a prática arquiteturais. São, aqui, questionados os modernistas da primeira geração, especialmente aqueles que fundaram o Bauhaus - o Grande Atelier do século XX - e aqueles que sofreram sua influência. $A$ rejeição da tradição, a produção de outras formas e o emprego sistemático dos novos materiais, o "funcionalismo absoluto "assim como a pesquisa da integração de todas "as atividades de um lugar" nāo tem mais força de regra. Charles Jencks exprime esse fato, sublinhando "a inversāo e a modifi- 
cação parciais da antiga linguagem arquitetural" A formulaçāo é atenuada, no momento em que as "contradiçōes na arquitetura" se manifestam com força e vigor. O pós-moderno arquitetural se caracteriza particularmente por suas alusōes ao passado, suas reminiscências históricas. $O$ novo impulso da arquitetura religiosa nos Estados Unidos é exemplar; ela rompe com a produção "autenticamente nacional" que, até época recente, foi "profundamente racional, empírica e utilitária"; ela evoca alusivamente as catedrais medievais, as basílicas da Renascença italiana, ou as igrejas rurais anglicanas; ela emprega mais o simbolismo religioso e as referências litúrgicas. Seus promotores "os arquitetos da escola metafísica" abrem, como foi dito, "as portas de uma era pós-moderna tingida de romantismo"

O pensamento pós-moderno atingiu as artes e a cultura no sentido lato, a literatura, certos modos de conhecimento e a filosofia. Ma sua versão mais teórica, ele se inspira, inicialmente, na dialética negativa da Escola de Frankfurt e dos trabalhos de J. HABERMAS que em sua contribuição. menciona aqueles "que consideram ter deixado para traz todos os paradigmas para poder entrar na clareira anárquica da pós-modernidade". Ele prevê a "desconfiança face as grandes sistematizaçōes e generalizaçōes" e anota por sua vez, relacionando à filosofia, o desenvolvimento de um sincretismo que integra no saber "às vezes de modo apressado e numa simultaneidade que não guia nenhuma escolha, ... o que foi até aqui rechaçado". J.-F. LYOTARD opõe uma modernidade "crítica" a uma pós-modernidade que "seria, antes, empiriocrítico ou pragmatista" Ele apresenta o pós-modernismo sob o aspecto de um "estado de espírito" quer dizer como um modo de descrever a mudança das sociedades, das culturas e do saber desde o corte dos anos cinquenta, momento em que o pós- guerra termina, momento de abertura das expansōes em todas os domínios da ação e das transformaçóes societais as mais generalizadas. Este estado intelectual age como um provocador de rejeiçāo: recusa das representaçōes unívocas do mundo, das visōes totalizantes, dos dogmas e, também, dos reconhecimentos e das afirmaçōes de sentido. Ele aparece como um dissolução dos referenciais, uma mistura das maneiras de ver e de significar, uma flutuaçāo das teorias. LYOTARD assinala o risco que, segundo ele, se impōe hoje ao pensamento filosófico. É preciso evitar o "pragmatismo positivista ambiente" tanto quanto o dogmatismo. Ambos são hegemônicos, a única resposta possível neste instante é a de operar pela "micrologia".

A noção de "pós-moderno" reuniu a grande série de escolas de pensamento, como as dos "antigos" dos "modernos" dos "estruturalistas" dos "marxistas" dos "existencialistas" das "feministas", etc., tāo bem descritas na obra de Dick Peet, Modern Geographical Thought, publicado em 1998. O pós-modernismo tornou-se uma corrente tangível, compreensível num único olhar, e suscetível de uma aprendizagem metódica. (Tabela 1)

\section{O pensamento pós-moderno na geografia humana}

Desde meados de 1980, os novos campos de força das ciências sociais aparecem em "ismos": pós-estruturalismo, feminismo, pós-modernismo. Os geógrafos (essencialmente anglo-saxōes) iniciam um debate com as ciências sociais e com a filosofia. O pós-modernismo está definitivamente ancorado na disciplina graças a alguns geógrafos de primeiro plano como David Harvey, Michael Dear, Ed. Soja ou Derek Gregory. Na França, Paul CLAVAL (1992) traz uma contribuiçāo importante, mas outros se interessam também, notadamente Augustin Berque, Vicent Berdoulay ou Jean-François Staszak. Com Ulf Strohmayer, nós apresentamos a evolução a mais recente da pesquisa e o debate em 1997 (BENKO, STROHMAYER, 1997) ${ }^{3}$. A discussāo é ao mesmo tempo volumosa e caótica, e se desenvolve em vários planos teóricos, indo da "nova geografia cultural" (qualitativa, etnográfica e individualista) às idéias "humanistas" passando pelos argumentos fundados sobre as mudanças econômicas.

E. GRAHAM (1995) menciona três modos nos quais os geógrafos reorientaram o desafio pro- 


\section{0 \\ 1980 \\ 1990 \\ 2000 \\ FILOSOFIA \\ LYOTARD, JAMESON, VATTIMO, WELLMER, HABERMAS, RORTY, BERMAN, RABINOW, BOISVERT, RUBY, FLAX, M. TAYLOR, NORRIS, \\ C. TALOR, FERRY, KELLNER,...}

SOCIOLOGIA

GIDDENS, LASH, LIPOVETSKY, BAUMAN, AUGÉ, URRY, FEATHERSTONE, SHIELDS, S. HALL, CHAMBERS, HARAWAY, SMART, TURNER, TOURAINE, BALANDIER, MAFFESOLI, GOTTDIENER, TORRES, BERTENS, ...

\section{ARQUITETURA}

$$
\text { JENCKS, PORTOGUESI, VENTURI, EISENMANN, TSCHUMI, LE DANTEC,... }
$$

ARTES E LETRAS JAMESON, ECO, WHEALE, FLOTZINGER, ALTIEIRI, HASSAN, KRAUSS, BARTH, HUTCHEON, PATERSON, MESCHONNIC, ...

URBANISMO SOJA, DEAR, COOKE, ELLIN, ZUKIN, SASSEN,...

GEOGRAFIA

DEAR, GREGORY, HARVEY, SOJA, CURRY, STROHMAYER, CLAVAL, BERQUE, BERDOULAY, BENKO, STASZAK, DOEL, GRAHAM, GIBSON, COOKE, OLSSON, ENTRIKIN, HANYAH, JONES, PRED, CRESSWELL, SLATER, DUPONT, DEUTSCHE, MASSEY, PEET, HARLEY, PHILO,GIBSON, BARYES, COSGROVE, SAYER, DUCAN, SANTOS,...

Tabela 1 - Os grandes temas e os principais autores da pós-modernidade (pró ou contra) desde os anos de 1970 (uma seleçāo indicativa)

posto por Michael DEAR, no final dos anos 80 , e que consistia em apreender as oportunidades oferecidas pelo pós-modernismo:

1. Levar em conta a limitação que consiste em aceitar, sem críticas, certos aspectos do pensamento pós-moderno e a integrá-los nas especialidades existentes da geografia humana.

2. Uma confrontação com o pensamento dominante das ciências sociais e das ciências humanas, "através de um exame crítico de certos aspectos do pós-modernismo ou pela exploração de diversas filosofias européias, permitindo colocar em evidência vários ramos do pós-modernismo".

3. Uma reação enérgica inscrevendo-se, às vezes, em oposição com ao apelo de Dear, convidando a reconstrução da geografia humana em resposta ao "desafio pós-moderno". Assim HARVEY (1987) rejeitou vigorosamente tanto o pós-modernismo quanto o realismo:

\begin{abstract}
"A filosofia pós-moderna nāo nos incita somente a aceitar, mas mesmo a nos inspirar na fragmentaçáo e na cacofonia das vozes, através das quais os dilemas do mundo contemporâneo se exprimem. Ela nos faz aceitar as reificaçōes e as partições, indo mesmo até a glorificar os fetichismos da localidade, do lugar ou do grupo de pressāo social. Essa retórica é perigosa porque ela evita enfrentar as realidades da economia política e as circunstâncias do poder mundial".
\end{abstract}

Segundo uma análise lexical (ver JEANNERET, 1998), o pós-moderno está ligado a uma corrente social, a uma postura teórica, a um espírito, a um estilo, ou ainda a um método. Quer dizer que, no debate de idéias, "ser pós-moderno" significa pertencer a certos meios e adotar uma certa postura intelectual, típica mas indefinida. Trata-se antes de um estilo que de uma doutrina. Como dizia Louis Duppont, os "pomos" são conhecidos por ser "po- 
liticamente corretos", relativistas em epistemologia e obscuros em expressão. A objetividade do conhecimento está em questão. Em resumo, os pós-modernos não são definiveis. (tabela 2 )

Tratando desse problema de definição, GREGORY (1987) identificou três postulados de base no pós-modernismo:

1. Ele representa um questionamento das "epistemologias da fundação" e da propensão ao eurocentrismo. Isto o coloca em instabilidade com o marxismo tradicional (Dear, Graham).

2. Essa tensão se traduz por seu afastamento dos modelos generalizantes e totalizantes.

3. Ele compreende uma interrogação teórica constante da desconstrução, quer dizer a dissecação de posiçōes teóricas antes aceitas em bloco.

Para o geógrafo de Cardiff, Phil Cooke, o pós-modernismo é a crítica do modernismo em todos os domínios. Essa rejeiçāo toma diversas formas, e COOKE (1990) as reagrupa em quatro abordagens:

1. "Apocalíptica". Aquela que se liga às posiçōes de Baudrillard sobre a dissoluçāo das estruturas da sociedade americana, em larga medida sob o efeito da "hegemonia das mídias" e os paralelos que podemos estabelecer com a queda dos regimes comunistas na Europa do Leste, por exemplo, o declínio ideológico e a dominação da imagerie mediática sobre as estruturas como sobre a classe social.

2. "Cética", É a idéia que o pós-modernismo é pouco ou nada mais que intençōes progressistas $e$, como apresenta Jameson em seus trabalhos, o pós-modernismo torna-se uma paródia do moderno, por exemplo, quando COOKE cita a arquitetura pós-moderna e as obras de autores como Rushdie, Garcia-Marquez e Fowles.

3. "Crítica". A crítica de Habermas é a mais virulenta, visto que considera o pós-modernismo como anarquizante e subversivo, na maneira com que ele aborda as teorias sociais universalistas. Entretanto, o fato de Habermas descrever a modernidade como "projeto inacabado" mostra que sua concepção da teoria social tem um caráter evolucionário e que ela não é nem tão con- servadora, nem ligada a um paradigma moderno sem concessōes, como o desejado pelas críticas de Lyotard.

4. "Pragmática". Essa perspectiva aceita as críticas da teoria social universal e as pressões pós-modernistas em favor de "diálogos múltiplos" ao invés de uma simples oposiçāo normal-anormal, mas, na versão que lhe dá Rorty, ela se revela mais otimista quanto ao desenvolvimento social. Esta maneira de ver supōe uma sociedade menos hierárquica e no entanto mais diferenciada, menos subordinada a um objetivo dado, menos exclusiva e portanto menos distanciada.

As características da concepção pós-moderna de uma sociedade futura foram resumidas por COOKE em dez pontos:

1. Propensão a se deixar dominar pela imagerie dos midias eletrônicas;

2. Sob o golpe de uma colonização do seu universo pelos mercados (econômico, político, social);

3. Tendência a celebrar o consumo como expressão pessoal;

4. Pluralidade cultural horizontal antes que vertical (massa/elite);

5. Polarização social devido aos distanciamentos acrescidos pelos rendimentos;

6. Dependente de um lugar nas suas concepçōes e na sua interpretação da realidade;

7. Democracia nos domínios sociais, culturais e econômicos, tanto quanto políticos;

8. Interação social sob o signo do pragmatismo antes que sob o da utopia;

9. Autonomia econômica acrescida graças as redes; 10. Menor dominação de mega-relatos militaristas ou guerreiros.

O pós-moderno recobre todos esses fenômenos. Ele conduz, em um único e mesmo movimento, a uma lógica cultural que valoriza relativismo e (in)diferença, a um conjunto de processos intelectuais que oferecem estruturaçōes significativas do mundo extremamente flutuantes $\mathrm{e}$ indeterminadas, em oposição à categorização moderna do mundo, e, enfim, a uma configuração de traços sociais que significaria a erupção de um movimento de descontinuidade no seio da condição moderna (mu- 


\begin{tabular}{|c|c|c|}
\hline Ano & Filosofia, artes e ciências sociais & Geografia \\
\hline 1977 & Jencks, C., "The language of post-modem architecture" & \\
\hline 1978 & $\begin{array}{l}\text { Venturi, v., et al., "L'enseignement de Las Vegas, ou le } \\
\text { symbolism oublié de la forme architecturale" }\end{array}$ & \\
\hline 1979 & Lyotard, F., "La condition postmodeme" & \\
\hline 1981 & Giddens, A., "Modemisme and Postmodemisme" & \\
\hline 1984 & $\begin{array}{l}\text { Jameson, } \mathrm{F} \text {, "Postmodemism, or the cultural logic of } \\
\text { late capitalism" }\end{array}$ & \\
\hline 1987 & $\begin{array}{l}\text { Vattimo, G., "La fin de la modemité. Nihilisme et } \\
\text { herméneutiqué dans la culture postmodeme" }\end{array}$ & $\begin{array}{l}\text { Gregory, D., "Postmodemism and the politics of social } \\
\text { theory" }\end{array}$ \\
\hline 1988 & & $\begin{array}{l}\text { Dear, M. J., "The postmodem challenge: } \\
\text { reconstructing human geography" }\end{array}$ \\
\hline 1989 & & $\begin{array}{l}\text { Harvey, D, "Conditions of Postmoderbity"; } \\
\text { Soja E., "Postmodem Geographies"; Harley J.B. } \\
\text { "Deconstructing the map" }\end{array}$ \\
\hline 1990 & $\begin{array}{l}\text { Ruby C, "Le champ de bataill postmodem, néo- } \\
\text { modeme" } \\
\text { Lash, S., Sociology of Postmodemism"; Giddens, A., } \\
\text { "The consequences of Modemity" }\end{array}$ & $\begin{array}{l}\text { Cooke, P., "Back to the Future, Modemity, } \\
\text { Postmodemity and Locality" } \\
\text { Cooke, P., "Modem urban theory in question" }\end{array}$ \\
\hline 1991 & $\begin{array}{l}\text { Jameson, F., "Postmodemism, or, the cultural logic of } \\
\text { Late Capitalism" }\end{array}$ & $\begin{array}{l}\text { Curry, M. R., "Postmodemism, Language and the } \\
\text { Strains of Modemism" }\end{array}$ \\
\hline 1992 & $\begin{array}{l}\text { Augé, M., "Non-lieux. Introduction à une anthropologie } \\
\text { de la surmodemité" }\end{array}$ & Claval, P., "Postmodemisme et Géographie" \\
\hline 1993 & Lyotard, J-F. "Moralités postmodemes" & $\begin{array}{l}\text { Sayer, A., "Postmodemist Thought in Geography: A } \\
\text { Realist View" }\end{array}$ \\
\hline 1995 & Bertens, H., "The Idea of the Postmodem" & $\begin{array}{l}\text { Watson, S., \& Gibson K., "Postmodem Cities and } \\
\text { Spaces"; Hannigan, J.A., "The postmodm city: a new } \\
\text { urbanization" }\end{array}$ \\
\hline 1996 & & Soja, E., "Third Space"; Ellin, N.," Postmodem Urbanism" \\
\hline 1997 & $\begin{array}{l}\text { "De la modemité à la postmodemité", Sciences } \\
\text { Humaines, } 73\end{array}$ & $\begin{array}{l}\text { Benko, G., \& Strohmayer U., "Space and Social } \\
\text { Theory: Interpreting Modemity and Postmodemity" }\end{array}$ \\
\hline 1998 & $\begin{array}{l}\text { Numéro sur la postmodemité, European } \\
\text { Review, } 6,1\end{array}$ & $\begin{array}{l}\text { Dear, M., \& Flusty S., "Postmodem Urbanism"; Berger, } \\
\text { A. A., "The postmodemism Presence. Readings on } \\
\text { Postmodemism in American Culture and Society" }\end{array}$ \\
\hline 1999 & & Soja, E., "Postmetropolis" \\
\hline
\end{tabular}

Tabela 2: Algumas etapas da história da literatura sobre a pós-modernidade 
danças dos sistemas produtivos e crise do trabalho, eclipse da historicidade diante da atemporalidade do efêmero, crise do individualismo moderno e onipresença da cultura narcisista de massa, etc.). Dito de outro modo, a condição pós-moderna evoca uma visão/mobilidade cultural, uma mutação intelectual no seio do humanismo ocidental e uma experiência histórica (de sensibilidade) particular, ancorada num suporte histórico específico. Notadamente, ela se revela a expressão de uma reconciliaçāo confessa com o mundo do fetichismo mercantil, a atitude de desculpabilização face às contradições da modernidade e mesmo da tradição de "enfraquecimento" da herança moderna.

A geografia pós-moderna utiliza três métodos (ou técnicas) essenciais à sua diversidade de posiçōes teóricas.

Primeiramente, a desconstrução, retomando a idéia de Derrida para a análise do texto. (Notamos que os três pensadores, os mais influentes do novo movimento de idéias da geografia são os franceses Derrida, Lacan e Foucault). Três elementos chaves podem iluminar esta concepção filosófica ligada a linguagem:

* os textos, como a linguagem, são marcados pela instabilidade e indeterminação do sentido;

* dada esta instabilidade e esta indeterminação, nem a filosofia nem a crítica podem se prevalecer de uma autoridade particular no que concerne à interpretação textual;

* a interpretaçăo é uma atividade que se pratica "de modo selvagem" e que se refere mais à prática de um jogo do que a uma análise.

O principal ponto é a supressão da ilusão de uma significação estável ou de uma interpretação única do texto. Na geografia, essa idéia é aplicável, além da linguagem, à representação cartográfica, como fez J. B. HARLEY (1989):

l. Isto permite questionar o mito epistemológico criado pelos cartógrafos, segundo o qual haveria uma progressão cumulativa de uma ciência objetiva, capaz de explicar a realidade.

2. É possivel redefinir a importância social das cartas, acrescentando diferentes nuanças à compreensāo do poder que detém a representação cartográfica de ordenar o nosso mundo. Diferentes "leituras" podem fazer nascer discursos paralelos, mesmo concorrentes.

3. A aplicação de diferentes desconstruções pode estender o papel da cartografia no estudo interdisciplinar do texto e do saber.

A geografia pós-moderna tem duas outras preferências metodológicas, a análise do discurso e a narração (nesse espirito podemos ler, por exemplo, as obras de Barnes e Duncan ou de Curry). O novo dinamismo do pensamento geográfico se ordena em torno de uma nova lógica dos discursos, propondo também uma geografia mais imaginativa.

As novas orientaçōes da geografia humana tornam-se reveladoras. Além dos ideais, das ideologias e das ilusōes devastadas, formula-se uma investigação explorando todos os caminhos da escrita, relacionando a experiência dos "espaços explodidos" recorrendo a uma mobilidade que restitui a abundância dos eventos com desenvoltura $e$ ironia. Da modernidade à pós-modernidade, uma certa continuidade tem lugar. A segunda se exaspera dos aspectos da primeira, ela leva, ao extremo, sua retórica.

Todas as duas dão conta de uma subversão das paisagens sociais e culturais, de uma quebra das laços tecidos no passado entre os homens e os grupos e suas obras ou dos lugares, de uma tentativa de refazer os fragmentos significativos de um futuro a informar. Elas tentam uma exploração dos espaços mal ou nāo referenciados, ignorados ou quase. Elas desenraizam. As palavras de Ulisses no retorno de Ítaca poderiam ser pronunciadas abordando esses limites: "A terra da qual eu mortal vim?... E mesmo onde eu irei? "

É preciso concluir? Podemos tirar alguma conclusão correta? Não é seguro. Eu afirmo mesmo, seguramente não. Entretanto, certas idéias aparecem com força, no plano do método e no avanço do debate. Nós temos a chance de ter vivido, de viver hoje uma crise espetacular do mundo intelectual, um questionamento dos fundamentos teóricos de toda orientação moderna do pensamento. Se o termo pós-modernidade aparece agora como um dos gritos de conversão dos anos 80 e 
90, bem esperto quem poderá dizer o que acontecerá. Nós podemos seguramente apostar no seu declínio. Todavia fenômenos assim insólitos que... a lentidão da circulação das idéias lhes assegura ressurgências imprevistas, como uma atualidade fatídica ou uma sobrevivência enigmática.

O pós-moderno aparece finalmente como um significante livre, paradoxal porque essencialmente imaginário ou se nós preferimos como uma ficção conceitual, uma categoria que é da ordem do como se... Tudo se passa como se o futuro tivesse se tornado um lugar vazio... Façamos como se a modernidade estivesse acabada... Para ver!

Nem voluntarismo nem ativismo, o procedimento pós-moderno é antes uma paixão do "tecer das alteridades", projetando seus ângulos. O modelo da modernidade seria apenas um traço insistente. E por isto que construção, desconstrução e reconstrução seriam condensadas num mesmo gesto. O pensamento pós-moderno corre o risco de ser assimilado a um metadiscurso em seu próprio projeto de aproximar a vida da experiência. De fato, ele vive dessa oscilação: ele torna-se então uma forma indefinivel, "sismográfica", apto a se abrir a empiria da sensibilidade estética e social. Em seus avanços como em seus impasses, ele enfraquece o ato pelo qual a racionalização dos discursos invalida o que está se esboçando hoje. Seu contexto de origem, que é a modernidade, não está sendo negado mas alterado para que a liberdade - que por sua vez permitiu a criatividade seja preservada.

Uma das grandes questōes de nossa disciplina é atualmente: como mensurar a relação complexa entre os movimentos que agitaram, e agitam sempre, a geografia e os impasses da modernidade? Talvez sejam estas as sirenes do pós-modernismo que suscitam entre muitos geógrafos um recuo em relação à pesquisa de quadros teóricos gerais? Parece que o pensamento geográfico abraçou tanto o modernismo (como por exemplo com a "revolução quantitativa") como o pós-modernismo (notadamente com a explosão das teorias ou a preocupação pluralista). Conhecemos a promessa de felicidade que fazia o modernismo recorrer a uma autonomização das esferas da ciência, da moral e da arte, na busca de uma síntese superior sempre adiada. Cada vez menos as pessoas acreditavam nessa possibilidade; é o fim dos consensos em torno de algumas idéias mobilizadoras (BERDOULAY, 1988). A Razão bate em retirada e a ciência está em crise. No entanto, trata-se com efeito de uma ciência positivista que se coloca contra o relato. Mesmo em seus aspectos aparentemente os mais racionais ou formalizados, as ciências sociais repousam sobre um certo número de mitos fundadores (CLAVAL, 1980), contados em alguns grandes Relatos. A geografia, a exemplo de outras ciências, é de natureza narrativa (BERDOULAY, 1988). O pluralismo do discurso geográfico se impóe então, e está aí um desafio da análise epistemológica, pois as formas do discurso, assim como o sentido, mantém relaçōes múltiplas e nāo unívocas. A esta conclusão de estilo "pós-moderno" faz eco uma visão análoga daquilo que se passa na sociedade: atomização dos indivíduos e recuo em solidariedades flutuantes e circunstanciais.

O pensamento geográfico se encontra por sua vez questionado. Os geógrafos devem portanto redescobrir os laços entre os lugares e as práticas democráticas, como afirma Vincent Berdoulay: uns como os outros, no nível científico como no cotidiano, não poderão escapar aos jogos do discurso. Moderno ou pós-moderno, é a questāo que os geógrafos se colocam hoje.

Pós-modernidade ou pós-modernismo e geografia! Muitos geógrafos dirão que "não é a geografia". Todavia se existe um só geógrafo na França que jamais pronunciou esta frase é certamente Paul Claval. 
${ }^{1}$ Este artigo foi publicado em francês, em uma primeira versão, em 1999, numa obra oferecida a Paul Claval, por sua aposentadoria em 1988. (Pitte J.-R., Sanguin A.-L., eds., 1999, Geographie et Liberté. Mélages offerts à Paul Claval, Paris, L' Harmattan).

2 O caso Sokal explodiu quando um físico da Universidade de Nova York, Alan Sokal, confessou que um artigo que ele havia publicado em 1996, na prestigiada revista Social Text por ocasião de um número especial sobre a " guerra das ciências " - " Transgredir as fronteiras em direçāo a uma hermenêutica transformadora da gravitação quântica " - nāo era, com efeito, senão uma paródia, um monte de clichés e de absurdos emprestados dos autores em voga, entre os quais muitos intelectuais franceses (Baudrillard, Derrida, Lacan, Virilio, entre outros) Brincadeira ! Mão ! Suas intençōes mais sérias foram desenvolvidas no seu livro Impostures Intelectuelles, (Paris, Odile Jacob, 1997) em colaboraçāo com Jean Bricmont , físico belga. $O$ caso sacudiu o meio intelectual francês e teve múltiplas repercussōes.

3 Benko, Georges. In: Revista do Departamento de Geografia, Sāo Paulo, Humanitas, 1999, n.o 13. (no prelo).

\section{Bibliografia}

BARNES, T.J. \& DUNCAN J. S. Writing Worlds. Discourse, text and metaphor in therepresentation of landscape. London. Routledge. 1992.

BENKO, G \&, STROHMAYER, U. Space and Social Theory. Interpreting Modemity and Posimodernity. Oxford. Blackwell. 1997.pp 400.

BERDOULA, Y. V. Des mots et des lieux. La dynamique du discours géographique. Paris. Ed. du CNRS. 1988.

BERTENS, H. The Idea of the Postmodern. London. Routledge. 1995.

CLAVAL, P. Les mythes fondateurs des sciences sociales. Paris. PUF. 1980.

CLAVAL, P. Postmodernisme et géographie. Géographie et Cultures. 4, 3-24. 1992

COOKE, P. Modern urban theory in question. Transactions, Institute of British Geographeers, 15, 3, 331-343. 1990.

CURRY, M. R. The work in the World: Geographical Practice and the Written Word. Minneapolis. University of Minnesota Press. 1996.

DEAR, M. J. The postmodem challenge: reconstructing human geography. Transactions of the Institute of British Geographers, 13, 262274. 1988.
DEAR, M. J. \& FLUSTY S. "Postmodern Urbanism" Annals of the Association of American Geographers, 88, 1, 50-72. 1998.

DERRIDA, J. De la grammatologie. Paris. Munuit. 1967. ENTRIKIN, J. N. The betweenness of place. Towards a geography of modernity. Baltimore John Hopkins University Press. 1991.

GIDDENS, A. The consequences of modernity, Cambridge, Polity Press. 1990.

GRAHAM, E. Postmodernism and the possibility of a new human geography, Scottish Geographical Magazine, 111, 175-178. 1995.

GREGORY, D. Postmodernism and the politics of social theory, Environment and Planing D: Society and Space.5, 3, 245-248.1987.

HABERMAS, J. Modernity versus postmodernity, New German Critique, 22, 3-14. 1981.

HANNIGAN, J. A. The postmodern city: a new urbanisation, Current Sociology, 43, 1, 152214. 1995.

HARLEY, J. B. Deconstructing the map, Cartographica, 26, 1-20. 1989.

HARVEY, D. Three myths in search of reality in urban studies. Environment and Planning D: Society and Space 5, (4), 367-376. 1987. 
HARVEY, D. The condition of Postmodernism.

Oxford. Basil Blackwell. 1989.

JAMESON, F. Postmodernism, or the cultural logic of late capitalism. New Left Review, 146, 5365. 1984.

JEANNERET, Y. L'affaire Sokal ou la querelle des impostures. Paris. PUF. 1998.
LYOTARD, J-F. La condition postmodern. Paris. /ed. Minuit. 1979.

SOJA, E. W. Postmodern Geographies. London. Verso. 1989.

SOJA, E. W. Postmetropolis. Oxford. Blackwell. 1999. 